\title{
Hermeneutical Phenomenology and the Philosophy of Science
}

Patrick A. Heelan

Georgetown University, heelanp@georgetown.edu

Follow this and additional works at: https://fordham.bepress.com/phil_research

Part of the Continental Philosophy Commons, and the Philosophy of Science Commons

\section{Recommended Citation}

Heelan, Patrick A., "Hermeneutical Phenomenology and the Philosophy of Science" (1991). Research Resources. 11. https://fordham.bepress.com/phil_research/11

This Article is brought to you for free and open access by the Hermeneutic and Phenomenological Philosophies of Science at DigitalResearch@Fordham. It has been accepted for inclusion in Research Resources by an authorized administrator of DigitalResearch@Fordham.

For more information, please contact considine@fordham.edu. 
Heelan, Patrick, "Hermeneutical Phenomenology and the Philosophy of Science," in Silverman, Hugh (ed.), Gadamer and Hermeneutics: Science, Culture, and Literature, (New York: Routledge, 1991). pp. 213-228

\section{HERMENEUTICAL PHENOMENOLOGY AND THE PHILOSOPHY OF SCIENCE}

\section{PATRICK A. HEELAN}

\section{PART I: Continental and Analytic Philosophy of Science Compared}

The two most characteristic interests of continental philosophy ${ }^{1}$ are (1) its preoccupation with the problem of the "constitution" of knowledge, and (2) the effect of the historical and cultural world context of science on the "social constitution" of scientific knowledge. Such constitution is "hermeneutical," when it essentially involves language, natural and artifactual symbols, and historical communities of interpreters.

Continental philosophy from the start sees science as an institution in a cultural, historical, and hermeneutical setting. The domain of its discourse is values, subjectivity, Life Worlds, history, and society, as these affect the constitution of scientific knowledge. Its notion of truth is that which pertains to history, political power, and culture. Its concern with science is to interpret its historical conditions within human society--usually in Western culture. ${ }^{2}$ Science, from this perspective, is a human, social--and fallible--enterprise. ${ }^{3} \mathrm{~A}$ concern of continental philosophy of science will include social failure as a possible indictment of scientific practice.

In contrast, the most characteristic interest of analytic philosophy is its concern with objectivity and truth, and its preference for the methods of formal logic.

Analytic philosophy from the start sees science as mankind's most successful truth enterprise, the fulfilment of a classical Aristotelian --and Platonic--desire for perfect knowledge, theoria. ${ }^{4}$ Analytic philosophy--before its widespread decline into relativism--had confidence in the power of abstract 
reason and of experimental methods to discover the objective truth that is beyond history, culture, values, subjectivity, and power. ${ }^{5}$

The logic and methodologies of the physical sciences are generally not a matter of dispute for continental philosophy. With respect to these questions, continental philosophers generally defer to experts who--it is assumed--are analytic philosophers of science. ${ }^{6}$ This surface agreement about the "logic of science" focusses the area of dispute on the principal domain of difference, that of metaphysics--of the human knower, of the known world, and of the knowing act. In particular, the actual dispute focusses on whether science is capable of delivering a metaphysics of nature or whether science is historically and socially constituted for some other goal than metaphysics-- more precisely, than a classical metaphysics.

Analytic philosophy generally defends the fundamental position that science is a knowledge of a privileged kind, not deriving from and not responsible to the projects and values of the Western cultural world or--to use Sellars's term-the Manifest Images of our culture ${ }^{7}$; rather, it constitutes a socially and historically independent account of reality, more reliable than any given so far. This Scientific Image of the world is truly then a classical metaphysics of nature.

Those claims come in conflict with the philosophical analysis of science as a social institution. Either society constitutes all of its institutions and has responsibility of them, or there is some privileged institution which (it is alleged) is not constituted by society and over which (it is alleged) society consequently has no responsibility or control. The latter conclusion is deeply troubling to the modern conscience remembering its recent political coming of age in which the Divine Right of patriarchal Princes and matriarchal Church were fought so stubbornly for the sake of human freedom--the freedom of the people to determine their own political lives and destiny. Science too must have a social constitution and, of course, a social conscience.

But how is science socially constituted? What kind of knowledge does it achieve? Continental philosophy actually finds the goal of science not in a metaphysics of nature but in society's pursuit of "technical" human interest. ${ }^{8}$ As Apel says,

The modern natural scientist must be guided by a technical interest in the sense of this apriori dependency of the problems upon instrumental verification. In this supra-individual, quasi-objective connection, his cognitive interest differs from that of the natural philosophy of the Greeks or the Renaissance and, in turn, that of Goethe or the romantics. And in this methodologically relevant interest, the whole of the exact natural sciences 
differ, above all, from the divergent practical interest and world engagement that lies at the basis of the so-called 'human sciences'. 9

This paper is directed towards taking issue with this statement. Its claim that natural science is deficient relative to natural philosophy stems from the fact that within the context of Western culture and history, scientific knowledge has value and significance predominantly--though certainly not exclusively-because of the power it confers. This prevalent Western mode of appropriation of science leaves open, however, other avenues of social appropriation--even the strictly philosophical, continental style.

Continental philosophy's rejection of science as a natural philosophy is stated succinctly by Maurice Merleau-Ponty in the Preface to his Phenomenogy of Perception: Edmund Husserl's directive "to return to the things themselves" 10 was, he says, "from the start a rejection of science."11 In what sense was this a rejection of science? It is principally a rejection of the presumption widespread in our culture and also among scientists that science alone is objective and capable of representing reality as it is unaffected by religious or racial myths, political expediency, historical forces, economic selfinterest and other forms of bias and prejudice. Science is uniquely on the path of truth and privileged on that account.

Continental philosophy's strenuous rejection of these scientistic claims is motivated by its fundamental metaphysical position: reality is the Life World, or just "world". This is the context of perceived nature and of social realities constituted by moral, social, political, and religious intentions; and it is the pervasive background or pre-understanding present in all human dealings with things and people. If scientific accounts are truly objective, then it follows that continental philosophy must regard them as not belonging by right to the world, but only by utility and convenience.

This, I want to point out, is a philosophical conclusion. To hold it does not mean (as some have argued) that the disciples of continental style philosophy are committed to quacks and alchemists rather than to modern medicine; like everyone else, they too prefer the medicine that works best. The question at issue is not a medical one (which heals best?) but a philosophical one (how do the entities of science--imperceptible to the unaided senses--relate to reality?). The lattter question, however, cannot be addressed until the more fundamental one has been answered: is reality to be understood classically and objectively or rather as socially constituted?

Continental philosophy usually claims that the entities of scientific theory that give to science its explanatory power have no reality because they are imperceptible to the unaided senses; it claims, they are just mathematical 
surrogates for real objects, useful models or metaphors to manipulate the environment. Continental philosophy's attack on scientism is then an attack on the metaphysical and moral claims of rational objective knowledge such as science claims to be. Its position is: if reality is the world, then the world is presupposed by science, and science inevitably returns --not to theory-- but to the world for its concrete reference. Merleau-Ponty expressed rhetorically this sentiment in a much-quoted passage: scientific objects, he says, are an "abstract and derivative sign-language, like map making [géographie] relative to the countryside in which we already know what a forest, a prairie, a river is." ${ }^{\prime 2}$ One may want to dispute the suggestion that science is like a map, and that forests, prairies, and rivers are scientific entities, but the judgment he expresses about science is typical of the writing of Martin Heidegger (in his later period), Hans-Georg Gadamer, Karl-Otto Apel, Jurgen Habermas, and the legions of Herbert Marcuse's and Friedrich Nietzsche's followers. ${ }^{13}$

Included in this group of science critics is by all accounts the later Husserl who, in The Crisis of European Science and Transcendental Phenomenology, ${ }^{14}$ led the phenomenological attack on the entrenched objectivism of current scientistic belief and practice. A closer reading of this late work, however, shows that the critique had also a parallel and more positive aim--to look at scientific research as a human way of being-in-the-world, and from this viewpoint to make a philosophical re-evaluation of natural science. ${ }^{15}$ The later Husserl should be counted as the leader of this secondary movement.

Phenomenology and Natural Science: This secondary movement by contrast springing from Husserl's Crisis gives to science a world building character. During his years at Göttingen (1901-1916), Husserl was a friend and colleague of the brilliant circle of mathematician-physicists who were to transform physics-- and all science-- in this century. Among them were Felix Klein, Richard Courant, Hermann Minkowski, Emmy Nöther, and Hermann Weyl, but their preeminent leader was David Hilbert. ${ }^{16}$ Hilbert, with the motto "physics is too difficult for physicists," advocated that the leadership of physics pass to mathematicians: for him, the definitive understanding of physical nature was to be provided by a universal mathematics of axiomatic theories. ${ }^{17}$ Theory making-- axiomatic in thrust-- became central to the method of the new physics. Such a view--let us call it the "Göttingen view"-- was shared by Husserl for whom the theory of theories is, as he says, axiomatic theory of of models or manifolds (Mannigfaltigkeiten).

Husserl, however, made a distinction between theory-making (as the method of physics) and metaphysics (as the traditional goal of science). While he agreed with the theoretical orientation of the Göttingen School of physics, he disagreed with the underlying--Cartesian or "Galilean"--metaphysics that was 
assumed by Hilbert and his colleagues. Such science, he charged, made the mistake of attempting to replace the world with a set of mathematical models.

That the metaphysics of science enriched the perceptual world with genuine- often new-- scientific phenomena, seemed evident to him. ${ }^{18}$ Such scientific phenomena, for example, as the Euclidean character of the physical world, ${ }^{19}$ are normed by theory (Euclidean geometry), and "realized" with the aid of scientific instruments (rulers, etc.). These technologies of construction and measurement prepare (or "corral") for scientific observation the phenomena (in this case) of physical geometry. Such phenomena are not ideal entities but perceptual phenomena that (in a sense to be discussed below) "fulfill" Euclidian theory. ${ }^{20}$

A new philosophy of science, Husserl intimated in the Crisis, can begin to address the experience of the "things themselves" of science; these are the genuine worldly phenomena of science, those which "fulfill" theory. Such phenomena enter the world as socially-constituted items, laden, like all the furniture of the world, with values and history, and wearing the accoutrements of social power or impotence. Focussing attention on those phenomena lays the groundwork for a new scientific realism, continental style. ${ }^{21}$ First among these new realists is the later Husserl. Among them also one could make a case for the Heidegger of Being and Time ${ }^{22}$ and for the Merleau-Ponty of The Visible and the Invisible. ${ }^{23}$ Some contemporary writers in this genre are listed among the references. ${ }^{24}$

Within phenomenology, then, there are two superficially opposing views about science. The first attacks the view of science as objective theory for being a peculiar historical idealogy prevalent in the classical Western tradition of philosophy and culture. The second attempts to correct that mistaken ideology by showing that scientific inquiry can and should be understood as constituted by the basic situation of the human being-in-the-world. At a deeper level, these views complement one another.

They agree fundamentally about the nature of the human subject as a social and historical being embodied-- as Merleau-Ponty said-- in detachable and undetachable sensory organs, ${ }^{25}$ about reality as the world, and about knowledge-- even of "theoretical states"-- as fulfilled (or--because the sense of this term is not yet clear-- "fulfilled")--in and through perception. In these three respects, continental philosophy differs profoundly from contemporary mainstream analytic philosophy of science.

PART II: Hermeneutical Phenomenology 
Hermeneutical phenomenology shares with phenomenology a set of characteristic concerns.

Firstly, the essence of being human is defined as a practical understanding of a historical world -- Life World -- an understanding that is worked out in and through language and other signs; human existence--that is, the experience of being a human subject--is that of being-in-the-world. ${ }^{26}$ Secondly, I take perception to be that form of knowing, by a subject's practical bodily insertion in historical world situations, in which reality horizons disclose themselves to subjects as referents for language. Thirdly, there is a hermeneutical phenomenology concerned with language and its extensions which provide both for mystery and for historical development in the uncovering of horizons of the world. Fourthly, perception has a certain primacy for establishing world, i.e., a primacy over ordinary language. ${ }^{27}$ By this I mean that ordinary language need not be accepted without criticism as the authority about world; it could-and should--be corrected and enriched by attention to the phenomenological constitution of the perceptual horizons it (ordinarily) designates.

Ordinary language assumes that the criteria of theoretical scientific language have a universal and overriding privilege. In my book, Space-Perception and the Philosophy of Science, I showed that visual space often has a geometry different from scientific geometry because it often serves a different cultural function from science.

Husserl proposed a method for analyzing the essence or eidos of a perceptual object which he called, the "method of the variation of profiles." 28 This method presupposes that a perceptual essence or eidos can be taken to be the symmetry or invariant of an organization of perceptual profiles--a profile being some way an object can appear to a situated perceiver. Husserl was familiar with Felix Klein's Erlanger Programme in which a geometrical object was defined as a figural symmetry or invariant under the spatial tranformation group which is both the transformation group of the coordinate reference frames (in which the object can be represented) and of its representations (within a coordinate frame). Applying Klein's model to the perceptual object, a perceptual object comes to be defined as the symmetry or invariant of one and the same transformation group which both permutes possible perceivers among themselves and possible object profiles among themselves. 


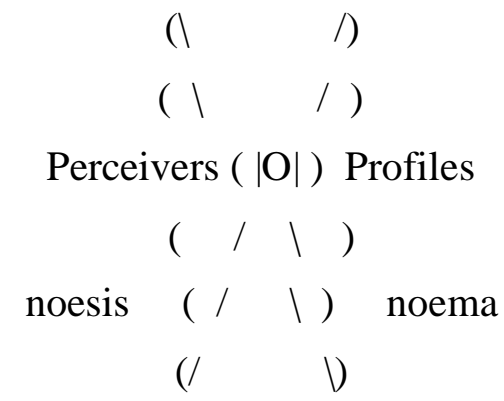

Figure 1: The perceptual object $\mathrm{O}$ is the symmetry or invariant relative to the transforamtion group among profiles and perceivers.

Note that the perceptual object (see figure 1) lies "in between" perceivers and profiles; it is a symmetry they both share. By this I mean that for every object transformation that leaves the perceiver untransformed, there is a correlative subject transformation that leaves the object untransformed. "Objective" and "subjective" transformations match one another, just as when one moves one's hand along a wall, one can either speak of the wall objectively, saying that parts of the wall succeed one another to the feel (the objective transformation) or one can speak of the hand subjectively, saying that it brings these parts of the wall in succession to the feel (the subjective transformation). The former objective version of the transformation (called "active" by physicists), changes the object; the latter subjective version of the transformation (called "passive" by physicists) changes the perceiver (as the object's frame of reference) in the reciprocal way. ${ }^{29}$

One and the same basic transformation group then defines the object and the subject. The subject so defined is represented by a cluster of active powers capable of recognizing, exploring, enjoying, or using the perceptual object whenever it is present and at hand. These powers may involve the use of instruments and readable technologies. ${ }^{30}$

Husserl's name for the objective transformation group is the noema; his name for the subjective transformation group is the noesis; each is a part of (what he called) the noetic-noematic structure. Noesis and noema share the same abstract group theoretic structure of being and action; they do not "mirror" one another passively, like picture and copy; their relationship is more like the dynamic one illustrated above by the finger touching the wall, or which Aristotle described when he said that the knower becomes the known by living 
the form of the known--the form of the known, in this case, would be the abstract transformation group.

It is clear from this account that a perceptual object is neither a sensory datum nor a formal construction out of sensory data. It is a symmetry within an established (but revisable) perceptual praxis and, consequently, already a semantic object tied in to a network of established semantical relations.

How does a scientific phenomenon come to "fulfill" its theoretical account in an act of observation? The classical tradition of physics from Galileo to Hilbert and from Newton to the Göttingen School assumed that the link between theory and observation was measurement. Measurement was supposed to be perfectible, indeed infinitely perfectible converging in the limit on the values which an objective and true theory would then accurately reflect. Even Husserl took this to be the case. ${ }^{31}$ However, as Duhem, Hesse, and others have shown, ${ }^{32}$ such an account of the link between measured phenomena and theory cannot be correct, for theory can never be uniquely determined by data. ${ }^{33}$

There is, however, a hermeneutical link ${ }^{34}$ between theory and data and that this link is to be understood partly on the model of language and partly on the model of that kind of interpretation which is exemplified in artistic performance. ${ }^{35}$ This will be taken up below.

A word about constitution or object formation: the constitution of a perceptual object $\mathrm{O}$ is studied from a standpoint "inside" the constituting act by the one constituting and experiencing the phenomenon--this study is a phenomenological ("eidetic" or "experimental") study. This role is indicated by $S_{x}$ in figure 2. Husserl's phenomenological method aims to define the eidos of such an object $\mathrm{O}$; this definition is abstractive, objectivizing, and thematizing account.

Eidetic definitions were criticized by Heidegger because they seemed to deny the ambiguity and flexibility of what is uncovered by understanding. Such accounts -- he called them, "theoretical" 36 -- have to be distinguished from scientifically theoretical accounts. Scientific theory works specifically only within the environment of a mathematical-experimental praxis. What this means will be discussed below. 


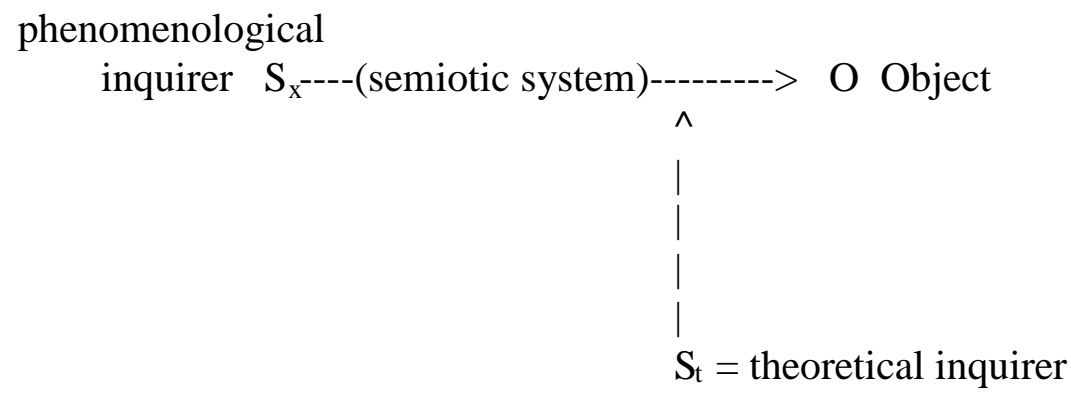

Figure 2. The two modes of inquiry into perception, the phenomenological role $S_{x}$ and the scientific theoretical-explanatory role $S_{t}$

Turning to figure 2: $S_{\mathrm{x}}$ is the phenomenological (eidetic or experimental) inquirer; $S_{t}$ is the theoretical inquirer. The constituting action of $S_{x}$ can be studied as a special kind of human performance from a standpoint "outside" of $S_{x}$--indicated by $S_{t}$; this would focus, for example, on the structural and semiotic conditions pertinent to the performance of the act of perception. $S_{x}$ experiences the phenomenon, while $S_{t}$ (as we shall see) "explains" the phenomenon. The characteristic feature of this explanation is that it produces a mathematical theory of those aspects of the object accessible to the instruments of our inquiry--technological instruments in experimental science, sensory in unaided perception. Such a theory has the characteristics of a scientific theory, and its explanatory role is a scientific one. We can compare such a theory to a "musical score," that is interpreted by $\mathrm{S}_{\mathrm{x}}$ 's performance in the medium of the instruments used--but more of this below.

What the theory refers to is indicated in figure 2 by the parenthesis "(semiotic system)", this is some underlying "score," "text," or "code" that directs the performance -- $S_{x}$ 's performance -- of the perceptual act. Such a semiotic system is envisaged not as part of an epistemological analysis (by $S_{\mathrm{x}}$ ) of the performance, but as part of its ontological structure (as judged by $S_{t}$ ). Such performance is hermeneutical in a new and existential way, and one not too far from that which Heidegger placed at the root of all knowledge.

The semiotic system implicit in the performance directs the eidetic functions of $\mathrm{S}_{\mathrm{x}}$ 's activity in an appropriate way--actually (we surmise) according to the way a skilled performance like a musical interpretation is guided by its "score" without, however, being entirely defined by its "score." The score of a piece of music is not unique but depends on the social-historical-cultural context (instruments, audience, conditions of recital, etc.) for the realization of the piece of music, for a piece of music is a historical entity, different from its 
score and the context of its performance. It would not then be surprising to find--as we do--that perception's "score" is no more accessible to a phenomenological analysis by $S_{\mathrm{x}}$ than a musical score is to the well-practiced player or singer. The (musical) score or (perceptual) "score" is not part of what is first known and then acted upon, but is rather one of the ontological conditions of possibility of the perceptual act.

Such an account is a "theory of the perceptual object," and has the character of a scientific theoretical-explanatory analysis. Its effect is not reduce the perceptual object to something merely there, but rather it addresses the perceptual object indirectly (through $S_{t}$ ) by describing a set of formal semiotic conditions for a perceptual performance terminating in such an object as perceived by $S_{x}$. How such a theory is implemented in the world in a particular medium at a particular place and time gives an existential hermeneutic account of perception.

The term "hermeneutics" is taken here in a new and extended sense suggested by Heidegger's transformation of phenomenological inquiry in Being and Time. Consider his example of the hammer. ${ }^{37}$ The hammer reveals itself as hammer while it is being used for hammering, but when being so used the character of being a hammer -- its eidos -- hides itself from the user within the transparency of the action executed. Just as the score hides itself in the performance, so the eidos of the hammer hides itself in the execution of hammering. The eidos nevertheless is there, as a kind of theory that "explains" the hammer in the hammering. For $S_{x}$, there is an abstractive account of the hammer's eidos -- for Heideggger, a "theory," an eidos-theory. For $\mathrm{S}_{\mathrm{t}}$, theory means something different; it is any model or map of the structure internal to the instrument that makes hammering possible, e.g., the tool designer's blueprint; this enables the "musical score" of hammering to be performed.

Returning to perception: one surmises that the perceptual "score" for hammering includes neurophysiological, somatic, and environmental elements, as well as computational and other semiotic elements. Since a perceiver $S_{x}$ has very limited access to the way these help "shape" the phenomenon, the standpoint of the researcher $S_{t}$ is not that of the perceiver. $S_{x}$ and $S_{t}$ belong to different cognitive communities and they are engaged in totally different causal, hermeneutical, theoretical, and existential relationships to their respective subject matters. Neither assumes a universal transcendental viewpoint.

In every hermeneutical activity, there is a certain reciprocity, for example, between text and meaning, and between score and performance. Such reciprocity is called "the hermeneutical circle." 38 Consider $\mathrm{S}_{\mathrm{x}}$ : on the one hand, the "score" is (existentially) prior to what is perceived, it does not permit 
arbitrary objects to be constituted, it exercises a certain control over the possibilities of what can be presented to $S_{x}$ and recognized within any given perceptual medium for any given desired purpose. On the other hand, it is also (existentially) posterior to what is constituted, for the medium must be "tuned" to the possibilities of the "score," for only on that condition will the medium and "score" succeed in presenting to $S_{x}$ an object with the anticipated perceptual content. The necessity of such "tuning" makes perception a performance and a work of artistry.

Making perceptual sense of the world is an individual and social art that involves the ability to perform transformative motions in a medium so that a common, shareable, and repeatable experience of presence or absence, of successful involvement or frustration can be realized. These intention-laden motions and environmental clues or responses are a part of language in the constitutive sense and (as I shall hold) can be studied from the viewpoint of $S_{t}$ in a scientific theoretical-explanatory way. Although such abilities and resources may be sufficient for animal language, they are not, however, sufficient for human language. ${ }^{39}$

Spoken words and sentences -- paroles -- belonging to the home language of a human community enrich the common experience by linking present agents and speakers immersed in their current worldly involvements with exemplary epochs, spaces, personalities, and transactions adumbrated in the oral narrative resources of a culture. They bring ideal (or seemingly transcendental) normativity to the here and now, and make possible a self-perpetuating community characterized by repetitive short-term projects pursued against a background of permanent norms "given (as it were primordially)" together with the world. The world is now a set of projects "given" to humans within a traditional culture and to be fulfilled by repetition or reenactment (or -- to use Piaget's terms -- accomodation and assimilation). Such narratives permit the individual speaker to appropriate the norms of the group that share orally-- as parole-- the same home language.

Written language - language -- brings history into being by evoking the normative differences that existed between past communities and our own. It can also bring to our attention the existence of other knowledge communities than ours with different and alien norms. Thus, from written language, hermeneutics arises as the appropriate method to study questions of the kind: with respect to world, have past-- or alien-- communities maintained different reality norms from ours, and if so, with what reason? In constraints on human agency (on what is morally possible, just, and worth pursuing), have people pursued different norms, and if so, with what right? In the understanding of 
society (whether it has a direction, what this is or should be, and who should control it), can there be different legitimate views?

Challenged as we are by synchronic and diachronic pluralisms in perception, language, science, culture, and history, I argued in my Space-Perception and the Philosophy of Science, that such structures fit into the formal model of a lattice or quantum logic (not, as often taken, of sentences, but) of contextdependent descriptive languages. ${ }^{40}$ This led me to call for recognition of an epistemological principle normative for human knowing: disparate horizons and disparate languages do and should seek upper bounds in an extended quantum lattice. $^{41}$ This is one of the regulative principles suggested by a hermeneutical phenomenology of the scientific tradition.

PART III: Elements of a hermeneutical and phenomenological philosophy of natural science

A philosopher of science in the phenomenological or hermeneutical tradition would then be guided by a new thrust different from a philosopher in the analytic tradition, both in the choice of significant problems and in the manner in which these are treated. Such a philosopher would do research into constitutional problems, human embodied subjectivity, and world--Life World-as reality--problems that so not enter into the purview of analytic philosophy of science.

1. Experimental phenomena: In contrast with the dominant classical interest in scientific theory making, the new thrust would center on experimental phenomena and how these come to be constituted as perceptual objects. Central to such constitution is the dual and complementary roles of experimenter $\left(\mathrm{S}_{\mathrm{x}}\right)$ and theoretician $\left(\mathrm{S}_{\mathrm{t}}\right)$ : the theoretician tries to model mathematically the readable technologies used by the experimenter to develop an institutionalized praxis for the preparation and presentation of phenomena. The two processes dialogue with each other until (provisionally at least) the last word is spoken by the experimenter when a stable phenomenon of known symmetry is capable of being produced.

Such scientific phenomena are "dressed" for the world by standardized scientific instruments used as readable technologies; these contribute to the historical and social constitution of scientific phenomena as beings in the world. ${ }^{42}$ In this regard, what Merleau-Ponty says (in "Eye and Mind") is relevant: "our organs are no longer instruments, on the contrary, our instruments are detachable organs." 43 
2. Scientific theory: One often hears today that all observation whatsoever is "theory-laden." What is meant by theory-ladeness in this context is that whatever is observed (inside or outside of science) involves things which are not directly observed but are implied by the semantic network of the language. Such semantic connections are not of themselves scientific (i.e., explanatorytheoretical) connections, and do not constitute a theory, for they are to be found in natural language which is not a theory about the world but a description of it. A theory is rather about what underlies--"explains"--the objects of a descriptive semantic network. ${ }^{44}$

Are scientific phenomena theory-laden? What "theory-laden" meant is that the same names are used of observations as of elements of scientific theory. However, scientific phenomena can be recognized within the context of a standardized praxis without the observer having to know more about the theory than the names it uses. Such phenomena are more aptly called "praxis-laden" than "theory-laden," for the theory has become embodied and hides itself in a public praxis. Such embodied theories "dress" the phenomenon and such "dressing" can become the basis for a description of the phenomenon. The experimental phenomenon is not formally theory-laden, but praxis-laden and the product of an interpretative art. ${ }^{45}$

Scientific theory and scientific phenomena are related within the context of a hermeneutic of sign (data) and object (phenomenon). The hermeneutic is local, historical, contextual, and realizable only within a standard institutionalized praxis.

3. Perceptual Realism: The thesis of the primacy of perception entails that theory is justified by being used to naturalize new scientific phenomena in the perceptual world. ${ }^{46}$ Theory then is not just a technique for manipulating the environment, it is itself world-building in that it furnishes our world with new things. $^{47}$

4. Hermeneutical or Horizonal Realism: Turning to the current debates in epistemology and the philosophy of science, a form of Scientific Realism is defended here which I call "Hermeneutical Realism" or, to emphasize the primacy of perception, "Horizonal Realism," or Scientific (Phenomena) Realism whenever I want to stress its opposition to the Scientific (Theory) Realism of current controversies. ${ }^{48}$ This is opposed to the Instrumentalism of many phenomenologists and critical theorists.

5. History of science: The history of science is more than the history of scientific writings and discourse, including illustrations, mathematical models, or abstract theories; in addition, there is the history of the culture of laboratory instruments with special reference to readable technologies; for not through 
books, language, and pictures alone do explanatory scientific entities get their social and historical constitution as realities, but through the readable technologies by which they are "dressed" so as to become a naturalized part of the furniture of this world, laden with the ambiguity of a historical perception.

6. Complementarity and Modern Physics: Natural and naturalized objects of perception can equally be characterized by complementarity understood as the way some human embodiments--even non-technological ones--preclude the exercise of others, with the consequence that some kinds of phenomena can appear as "dressed" only in certain ways 49 ; e.g. the geometry of a space-time object is determined by the embodiment and interests we bring to it. ${ }^{50}$

7. The human knowledge community: The community of human knowers is then comprised of irreducible complementary subcommunities, linked by linguistic and nonlinguistic channels of intercommunication, and bound together--to the extent that bonds exist--by bonds of mutual trust, good will, and common goals, which mutually exclude, however, simultaneous access to common experiential horizons. ${ }^{51}$

8. Scientific explanation: Where then does this leave the account of explanation in the natural sciences? (1) In the first place, one has to distinguish carefully between (1a) the nomological or computational aspects of explanation which deal with correlations among phenomena, and (1b) the constitutional aspect of explanation which deals with the origins of phenomena. In the vocabulary of Ricoeur, Apel, and other continental philosophers, the former alone is called "explanation" and it is taken to be the characteristic of the natural sciences. The latter is called "understanding" and this is taken to be characteristic of the human sciences. ${ }^{52}$ It is clear that a more comprehensive account of the notion of explanation in the natural sciences employs both of these activities.

In addition, one would have to distinguish (2) between semantic and perceptual contexts--they are different, (3) between the perceptual contexts of natural world horizons (unaided by technologies) and those of naturalized world horizons in which readable technologies are used--when the last word is spoken, they are continuous and indistinguishable, and (4) among the respective communities of inquirers involved in the different phases of the inquiry, each in relation to perception with its different mode of embodiment and different hermeneutical interests--these are complementary. If the concept of explanation were to be so enlarged, it would be necessary to go beyond the semantics of mere truth-functional discourse to the practical dimension of discourse, and consequently to distinguish (5) between truth-functional sentential logic and a quantum logic of the existential contexts of discourse. ${ }^{53}$ 
Where does this leave the account of explanation in the natural sciences? It shows that if explanation is limited to (1a), i.e., to the causal, nomological, and deductive relationships among phenomena and their descriptions, then the phenomena in question cannot be natural pre-scientific phenomena as Logical Positivism and much of Logical Empiricism assumes, but naturalized scientific phenomena constituted by institutionalized processes of preparation and measurement. However, if the notion of explanation is enlarged (as it should) to include (1b), i.e., how scientific phenomena are constituted in local media, then explanation is no longer just computational or derivational, but it is historical, social, artistic, and hermeneutical. ${ }^{54}$ 


\section{REFERENCES}

Apel, Karl-Otto. 1980. Towards a Transformation of Philosophy. Trans. by G. Adey and D. Frisby. London and Boston: Routledge and Kegan Paul.

Bleicher, John. 1980. Contemporary Hermeneutics. Hermeneutics as Method, Philosophy, and Critique. London and Boston: Routledge and Kegan Paul.

Bleicher, John..1982. The Hermeneutic Imagination. London and Boston: Routledge and Kegan Paul.

Bruzina, Ronald, and Wilsire, Bruce (eds.). 1982. Phenomenology Dialogues and Bridges. Albany: SUNY Press.

Bubner, Rudiger. 1981. Modern German Philosophy. London and New York: Cambridge University Press.

Churchland, Paul. 1979. Scientific Realism and the Plasticity of Mind. Cambridge: Cambridge University Press.

Dreyfus, Hubert. 1980. "Holism and hermeneutics," Rev. Metaph. 34 (1980), pp. 3-24.

Duhem, Pierre. 1954. Aim and Structure of Physical Theory. Princeton: Princeton University Press.

Follesdal, Dagfinn. 1979. "Hermeneutics and the hypothetico-deductive method," Dialectica, 33 (1979), pp. 319-336.

Foucault, Michel. 1970. The Order of Things: An Archeology of the Human Sciences. New York: Random House.

Gadamer, Hans-Georg. 1975. Truth and Method. Trans. G. Barden and J. Cumming. New York: Seabury Press.

Gadamer, Hans-Georg. 1981. Reason in the Age of Science. Cambridge, Mass.: MIT Press.

Habermas, Jürgen. 1971. Knowledge and Human Interests. Trans. J.J. Shapiro. Boston: Beacon Press.

Hanson, N. Russell. 1961. Patterns of Discovery. Cambridge and New York: Cambridge University Press.

Heelan, Patrick. 1983a. Space-Perception and the Philosophy of Science. Berkeley and Los Angeles: University of California Press.

Heelan, Patrick. 1983b. "Natural science as a hermeneutic of instrumentation," The Philosophy of Science, 50 (1983), pp. 181-204.

Heelan, Patrick. 1983c. "Perception as a hermeneutical act," Review of Metaphysics, 37 (1983), pp. 61-75.

Heelan, Patrick. 1983d. "Natural science and Being-in-the-world," Man and World, 16 (1983), pp. 207-219.

Heelan, Patrick. 1987. "Husserl's Later Philosophy of Science," Philosophy of Science, vol. 54 (1987), pp. 368-390. 
Heelan, Patrick. 1988a. "A Heideggerian Meditation on Science and Art," in Hermeneutic Phenomenology, ed. J.J. Kockelmans. Washington, D.C. and Pittsburgh: University Press of America and CARP, 1988), pp. 257-275.

Heelan, Patrick. 1988b. "Experiment and Theory: Constitution and Reality," in The Journal of Philosophy, 85 (1988), pp. 515-524.

Heidegger, Martin. 1962. Being and Time. Trans by J. Macquarrie and E. Robinson. New York: Harper and Row.

Heidegger, Martin. 1967. What Is a Thing? Trans. by W.B. Barton, Jr. and V. Deutsch. Chicago: Regnery.

Heidegger, Martin. 1977. The Question Concerning Technology and Other Essays. Trans. by W. Lovitt. New York: Harper Colophon.

Hesse, Mary. 1980. Revolutions and Reconstructions in the Philosophy of Science. Bloomington: Indiana University Press.

Husserl, Edmund. 1952. Ideen zu einer reinen Phaenomenologie und phaenomenologische Philosophie, Book II: Phaenomenologische Untersuchungen zu Konstitution. Ed. M. Biemel. Husserliana, Vol. 4. The Hague: Nijhoff.

Husserl, Edmund. 1970a. Crisis of European Sciences and Transcendental Phenomenology. Trans. by D. Carr. Evanston: Northwestern University Press.

Husserl, Edmund. 1970b. "Origins of Geometry" pp. 353-378 in Husserl (1970a).

Husserl, Edmund. 1970c. Logical Investigations. Trans. by F.N. Finlay. 2 vols. Routledge and Kegan Paul.

Ihde, Don. 1979. Technics and Praxis. Dordrecht and Boston: Reidel.

Kisiel, Theodore. 1973. "On the dimensions of a phenomenology of science in Husserl and the young Doctor Heidegger," Jour. Brit. Soc. Phenom., 4 (1973), pp. 217-234.

Kisiel, Theodore. 1977. "Heidegger and new images of science," Res. Phenomenology, 7 (1977), pp. 162-181.

Knorr-Cetina, Karin. 1981. "Social and scientific method or what do we make of the distinction between the natural and social sciences?", Phil. Soc. Sci., 11 (1981), pp. 335-360.

Kockelmans, Joseph. 1985. Heidegger and Science. Pittsburgh and Washington, D.C.: CARP and University Presses of America.

Kockelmans, Joseph. 1986. "On the Hermeneutic Dimensions of Natural Science,” Etudes Phénoménologiques, \#3 (1986), pp. 33-81.

Kockelmans, Joseph. 1987. "On the Problem of Truth in the Sciences," Presidential Address, Proceedings and Addresses of the American Philosophical Associastion, vol. 61 (1987), pp. 5-26. 
Kockelmans, Joseph and Kisiel, Theodore (eds.) 1970. Phenomenology and the Natural Sciences. Evanston: Northwestern University Press.

Kuhn, Thomas, S. 1970. The Structure of Scientific Revolutions. 2nd ed. Chicago: Chicago University Press.

Latour, Bruno and Woolgar, Steve. 1979. Laboratory Life. London and Beverly Hills: Sage Publ.

Merleau-Ponty, Maurice. 1962. The Phenomenology of Perception. Trans. Colin Smith. London: Routledge and Kegan Paul.

Merleau-Ponty, Maurice. 1964a. The Primacy of Perception. Evanston: Northwestern University Press.

Merleau-Ponty, Maurice. 1964b. "Eye and Mind", in Merleau-Ponty (1964a), pp. 159-192.

Merleau-Ponty, Maurice. 1968. The Visible and the Invisible. Trans. A. Lingis. Evanston: Northwestern University Press.

Mulkay, Michael. 1979. Science and the Sociology of Knowledge. London and Boston: Allen and Unwin.

Peirce, Charles Sanders. 1931-1958. The Collected Papers of Charles Sanders Peirce. 8 vols. Vols. 1-6 ed. by Charles Hartshorne and Paul Weiss; vols. 78 ed. by Arthur Burks. Cambridge, Mass.: Harvard University Press.

Pavlovic, K.R. 1981. "Science and autonomy," Man and World, 14 (1981), pp. 127-140.

Reid, Constance. 1970. David Hilbert. New York: Springer-Verlag.

Ricoeur, Paul. 1978. The Philosophy of Paul Ricoeur: An Anthology of his Work. Boston: Beacon Press.

Ricoeur, Paul. 1981. Hermeneutics and the Human Sciences. Trans. by J.B. Thompson. Cambridge: Cambridge University Press.

Rorty, Richard. 1979. Philosophy and the Mirror of Nature. Princeton: Princeton University Press.

Rouse, Joseph. 1987. Knowledge and Power. Ithaca, NY: Cornell University Press.

Seigfried, Hans v. 1980. "Scientific realism and phenomenology," Zeit. $f$. Philosophische Forschung, 24 (1980), pp. 395-404.

Sellars, Wilfred. 1963. "Philosophy and the scientific image of man," in Science, Perception, and Reality. London: Routledge and Kegan Paul. Pp. 140.

Simpson, Lorenzo. 1983. "Science, language, and experience: reflections on the nature of self-understanding," Man and World, 16 (1983), pp. 25-42.

Ströker, Elizabeth. 1987. The Husserlian Foundations of Science. Washington D.C. : University Press of America and CARP.

Suppe, Fred. (ed.). 1974. The Structure of Scientific Theories. Urbana: University of Illinois Press. 
Toulmin, Stephen. 1960. Philosophy of Science. New York: Harper.

Toulmin, Stephen. 1972. Human Understanding, Vol. 1. Oxford: Clarendon Press.

Toulmin, Stephen. 1982 "The construal of reality: Criticism in modern and postmodern science," Critical Inquiry, 9 (1982), pp. 93-111.

Wigner, Eugene. 1967. Reflections and Symmetries. Indiana University Press.

Zucker, Francis J. 1982. "Phenomenological evidence and the 'Idea' of physics," in Bruzina et al. (1982), pp. 269-290.

\section{NOTES}

*This paper was originally written for the Research Conference on Continental and Anglo-American Philosophy: A New Relationship, organized by Stephen Toulmin and Paul Ricoeur at the University of Chicago (1984). I thank Stephen Toulmin, Hugh Silverman, Joseph Kockelmans and Lajla Lund for their comments on the paper; these have helped greatly in the revision of the original text.

${ }^{1}$. See the references for a listing of some of the more important works in this tradition. For an overview of contemporary German work on the philosophy of science, see Bubner (1981), pp. 69-154.

2. Cf the works of J. Ellul, M. Foucault, Marcuse, and others.

3. A view going back before psychoanalysis to Nietzsche and picked up later by many, such as G. Bachelard, M. Heidegger, H. Marcuse, and others.

${ }^{4}$. (Aristotelian) Theoria is a disinterested form of general knowledge often taken as the ideal of science; it is not, however, constituted by human life but it is (according to the classical authors) a sharing of the exemplary ideas of the Demiurge. Heidegger (1962) sees modern science as the heir to classical metaphysics, the metaphysics (as he says) of the merely "present-at-hand." Also see Gadamer's comments in (1975), p. 413, and Kockelmans (1985) and (1986).

5. Cf. Suppe (1974) for an excellent overview of the analytic tradition of the philosophy of science.

${ }^{6}$. Such are the background assumptions, say, of Apel, Gadamer, Bernstein, Habermas, and Heidegger. 
7. Sellars (1963).

8. Cf. Habermas, J. (1971); Apel (1980), who misreads Peirce in this respect; Gadamer (1981) and (1975), pp. 409-411. See Kockelmans (1985), chapter V, for an excellent review of Heidegger's thought on the mathesis of the natural sciences.

9 Apel (1980), p. 49.

10. Husserl (1970c), p. 252; see also Heelan (1987).

11. Merleau-Ponty (1962), p. viii.

12. Merleau-Ponty (1962), p. ix, my free translation.

13. See, for example, Gadamer (1975), pp. 409-411, and the works referenced below; see also Pavlovic (1981), and Simpson (1983).

14. Husserl (1970a); also prefigured in Husserl (1952).

15. Cf Zucker (1982).

16. Heelan (1987).

17. Cf. Reid (1970).

18. See Husserl (1970a), p. 55, and Zucker (1982).

19. Husserl (1970b).

20. Quotation marks usually signify that there is something problematical about the usual meaning of the term and includes a promise to deal with the problem below--or later.

21. Despite its different vocabulary, the thrust of this latter movement has much in common with a variety of contemporary Anglo-American movements (or counter-movements) that have all tended to undermine the traditional belief in the objectivity of science, and to give support instead to the view that science is a function of human life, social values, and historical-culturaltechnological environment. See, for example, Toulmin (1960, 1972); also the historical work of T.S. Kuhn, G. Holton, L. Fleck, and L. Laudan; the sociological studies of such as B. Barnes, D. Bloor, B. Latour, M. Mulkay, S. Shapin, and S. Woolgar (see Knorr-Cetina, 1981); and the critique of logical empiricism by J. Compton, P. Feyerabend, M. Grene, N. R. Hanson, M. Hesse, M. Polanyi, R. Rorty, S. Toulmin, G. von Wright, and M. Wartofsky (see Suppe, 1974 for summary).

22. Heidegger (1962). For a study of the implications of Heidegger's early views for a philosophy of natural science, see Seigfried (1980), Kisiel (1977), and Kockelmans (1985).

23. Merleau-Ponty (1964b, 1968); Ricoeur (1981). See also, for example, the referenced works of Compton, Dreyfus, Ihde, Kisiel, and Zucker, to mention a few, who share this project. 
24. Among writers currently working in the genre of a phenomenological philosophy of natural science are, to mention just a few, John J. Compton, Robert Crease, Hubert Dreyfus, Marjorie Grene, Gary Gutting, David Hemmendinger, Don Ihde, Theodore Kisiel, Joseph Kockelmans, Wolfe Mays, Joseph Rouse, Hans Seigfried, Elizabeth Ströker, and Francis Zucker. Not all of these would agree with the positions here enuntiated, but I believe all would appreciate their relevance to the basic problematic of a phenomenological philosophy of science. Among those who notably fail to exploit aggressively the positive implications of the insight that the standpoint of science cannot be objective and universal is, for example, Gadamer, cf Gadamer (1975), pp. 409411; also Pavlovic (1981), and Simpson (1983).

25. Merleau-Ponty (1964b), p. 178.

26. See Gadamer (1975), pp. 397-431.

27. See Heelan (1983a) and (1988).

28. See Husserl $(1952,1970 a)$. A perceptual essence is for Husserl the invariant (noematic) law among the set of profiles (perspectives) through which a perceptual object reveals itself to a perceiver who explores it actively (noetically) with his or her body. See also Heelan (1987) for an interpretation of these as related to the representations of active and passive transformation groups. For the notions of essence and specific essence, see Husserl (1952). 29 . See Wigner (1967) for a physicist's account of the importance of transformation groups in physics.

30. The constituting role of scientific technologies has generally been overlooked wherever science has been accepted, as it has been bymost writers in the phenomenological tradition, as a culmination of the classical tradition. See Kockelmans (1985), sect. 22 for the critique of technology that follows from this position. Heidegger (1977) begins with a critique of modern science and modern technology and eventually ends with something like the kind of resolution which lies at the basis of this paper.

31. See Heelan (1987).

32. Duhem (1954) and Hesse (1980) on the underdetermination of theory by data.

33. I make a terminological distinction between "datum" and "phenomenon"; a datum is to a phenomenon as a profile is to a perceptual object; thus, data, e.g., a set of measured values of $\mathrm{O}$, provide the profiles of the phenomenon $\mathrm{O}$ that is being measured.

34. The nature of this mediation is suggested by the view of the early Heidegger that all human knowledge is existentially hermeneutical.See Heidegger (1962) in which existential hermeneutics is introduced. Methodological hermeneutics is the traditional discipline which concerns itself 
with the meaning of signs. Once the signs are successfully interpreted, however, they become transparent and do not occupy a place in the objective perceptual field. It is in fact characteristic of a successful hermeneutic that the signs disappear from the objective field; it may sometimes be the case that the signs were never presented or understood as a system antecedent to being used interpretatively. Once a sign system is used successfully, it may be difficult to recover anew or perhaps uncover for the first time the objective system of signs that is being used; the difficulty of linguistic studies suggests this. Existential hermeneutics is the name for the ontological character of human understanding. I have proposed to give an account of this as structured by a relationship between objects meant and the underlying codes to which they are related. See Bleicher (1980) for a general overview, and Ricoeur (1981); also, for the last point, Heelan (1983b).

35. See Heelan (1983c) and (1988).

36. The Heideggerian notion of theory, as found, say, in Heidegger (1977) and the later works, is well articulated in Kockelmans (1985) and (1986).

37 . Heidegger (1962), p. 98.

38. See Heidegger (1962), pp. 188-195; also Gadamer (1975), Dreyfus (1980).

39. For Gadamer's view on the role of language in the making of a human world, see Gadamer (1975), pp. 397-447.

40. Heelan (1983a), chapters 10 and 13.

41. Cf Heidegger (1962), pp. 188-195.

42 . See Heelan (1983a), chap. 15. The "dressing" analogy is not to be pushed too far; there is no "naked" entity, just as there is no "naked" perceptual essence. A particular "dressing" is a particular set of perceptual profiles constituting a particular perceptual essence for the scientific entity.

43. Merleau-Ponty (1964b), p. 178.

44. Cf. Peirce on "Thirdness"; that something-- a sign--is taken to stand for something--an object $\underline{t--}$ by an interpretant -- the act of interpretation by a community of interpreters. See Peirce (1931-1958), vol. 1, 1.300-1.353, especially 1.338; also 2.228-2.308; for the interpretative character of perception and science, see 5.182-5.184.

45. See, for example, the discussion in Suppe (1974), pp. 125-190, and Heelan (1983a) and (1988b).

46. Many, such as Hanson and Churchland, make an analogous claim that science transforms the way we perceive the world. The argument they present is based solely on the kinematical aspects of the prescientific and scientific theories, and so the choice between the frames they offer to describe the sun is no more than a matter of convention, not revolutionary and with nothing to do with complementarity. However, there is a truly scientific difference between 
sun-centred and earth-centred theories because these are related to different laws of dynamics. To find a valid argument, one would chose to compare Aristotle (and the old dynamics) with Newton (and the new dynamics), instead of Kepler and Tycho Brahe for in the latter case the evidence was merely kinematical. See Hanson (1961), pp. 6f; and Churchland (1979), pp. 30-35, for their treatment of this question.

47. Heelan (1983a), chap. 11; this is also a position held by Peirce, see Peirce (1931-1958), 5.189-5.212.

48. See Heelan (1983b), (1983c), and (1983a), chapter 8.

49. Cf. Merleau-Ponty (1968), e.g., pp. 90-91, 94-95. It is interesting and significant that the term "complementarity" used by Merleau-Ponty and Apel is used with the conscious suggestion that such a sense could resolve the more than fifty year old enigma of what is called "complementarity" in quantum mechanics. This suggestion I believe is correct, and I have shown elsewhere how the peculiar logic of quantum mechanics, quantum logic, can be understood as the general logic of contextual embodied discourse within language. See Heelan (1983a), chapters 10, 11, and 13.

50. Heelan (1983a), Part I.

51. Cf Gadamer (1975), pp. 397-447, and Ricoeur (1981).

52. See Ricoeur (1981), pp. 145-164.

53. Note how this analysis contrasts with the the common assumption of continental philosophers such as Apel, Habermas, the early Merleau-Ponty, and by analytic philosophers such as Sellars, Rorty, Churchland, that problems in the philosophy of science center on the replacement of the semantics of natural perception (say, of heat-as-felt) by the semantics of scientific theory (say, of thermodynamics) rather than on the complementarity of such frameworks stemming from the embodied and hermeneutical character of acts of perceiving.

54. See Heelan (1983a), chap. 10. 